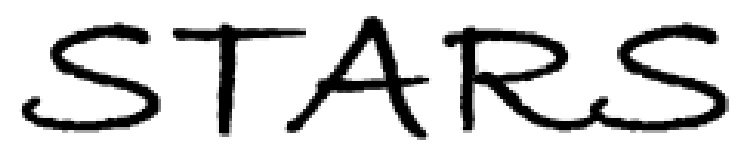

University of Central Florida

STARS

Faculty Scholarship and Creative Works

2008

\title{
Branching Out: Communication and Collaboration among Librarians at Multi-Campus Institutions
}

\author{
Tim Bottorff \\ University of Central Florida, timothy.bottorff@ucf.edu \\ Robbin Glaser \\ Troy University, robglaz08@yahoo.com \\ Andrew Todd \\ University of Central Florida, andrew.todd@ucf.edu \\ Barbara Alderman \\ University of Central Florida, Barbara.Alderman@ucf.edu
}

Part of the Library and Information Science Commons

Find similar works at: https://stars.library.ucf.edu/ucfscholar

University of Central Florida Libraries http://library.ucf.edu

This Paper is brought to you for free and open access by STARS. It has been accepted for inclusion in Faculty Scholarship and Creative Works by an authorized administrator of STARS. For more information, please contact STARS@ucf.edu.

\section{Original Citation}

Bottorff, T., Glaser, R., Todd, A., \& Alderman, B. (2008). Branching out: Communication and collaboration among librarians at multi-campus institutions. Journal of Library Administration 48(3-4), 329-363.

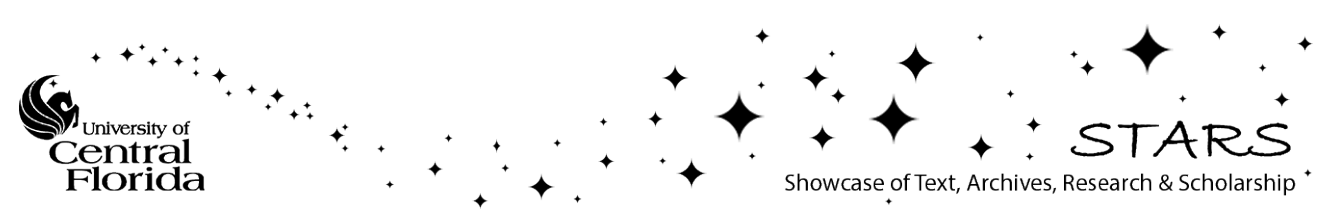




\title{
Branching Out: Communication and Collaboration among Librarians at Multi- Campus Institutions
}

\author{
Tim Bottorff \\ University of Central Florida, Rosen College campus \\ Robbin Glaser \\ Troy University, Dothan campus \\ Andrew Todd \\ University of Central Florida, Cocoa campus
}

Barbara Alderman

University of Central Florida, Cocoa and Palm Bay campuses

\begin{abstract}
Communication and collaboration are vital aspects of $21^{\text {st }}$ century librarianship, particularly for librarians in branch and regional settings who are often separated from their system colleagues by both physical distance and administrative structures. For this study, the authors conducted an exploratory survey to examine collaboration, communication, and networking behaviors and perceptions among librarians in multi-campus academic library systems. Results of this investigative study will lead to better understanding of these issues within the profession, suggest possible approaches and solutions for better models of communication and collaboration, and lay the groundwork for future research on these topics.
\end{abstract}

\section{Introduction}

Librarians at multi-campus academic institutions face special challenges and opportunities. As colleges and universities expand and improve, they naturally spread into larger geographic areas, often creating the need for library collections and services at locations that may be called "branch" (generally the preferred term in this paper), "regional," "area," "distant," "remote," "extended," "satellite," or any number of other terms. Whatever the terminology used, the provision of library services at branch campuses naturally creates the need for branch librarians, who are necessarily separated from their colleagues at other campuses through both physical distance and administrative structures. 
The effects of this physical and administrative separation among librarians at multi-campus institutions have thus far not been studied in depth. For example, do librarians at branch locations frequently feel "isolated" from their main campus colleagues? Are librarians within such institutions utilizing new technology to improve channels of communication and collaboration? Do all librarians within multi-campus institutions have roughly equal opportunities for collaboration, networking, and professional development activities? Answering these and other questions is critical for a profession challenged with adapting to an academic landscape in which traditional methods of teaching and learning are rapidly being displaced by more decentralized and virtual approaches.

In short, this study seeks to examine issues surrounding collaboration, communication, and networking among librarians in multi-campus academic library systems. The authors combine a literature review with the results of an exploratory survey in an attempt to better understand these difficult issues, to point the way towards possible approaches and solutions for the profession, and to lay the groundwork for future research.

\section{Literature Review}

There is little in the library literature on communication, collaboration, and networking, particularly among librarians at multi-campus institutions. Therefore, this literature review includes articles written for main campus librarians as well as branch librarians.

Of the three factors, communication is the most commonly found in the general literature. Communication "provides the means for problem solving, resolving conflicts, accomplishing change, and future planning” (Echavarria, 2001, p.23). However, communication requires complete inclusion. When only some people are included in the communication loop, an atmosphere of mistrust rather than group problem solving is the result. Including everyone applies to everyday tasks as well as sharing knowledge with colleagues (Echavarria, 2001).

Another benefit of communication is that it may help alleviate a sense of isolation. Even librarians located at a main campus but physically separated from the library can feel a sense of isolation (Crockett, 2000). Reiten and Fritts comment that within a main campus, some areas of librarianship may be physically removed from the library. They suggest that "this isolation, whether real or perceived, has led to the emergence of distance learning librarianship as a distinct area of librarianship" (2006, p. 399). To make isolation less of an issue, Crocket says librarians should keep communication lines open by participating in library-wide committees and attending library meetings (2000).

Collaboration among individual librarians has received relatively little treatment in the professional literature. For the purposes of this paper, collaboration is defined as to work "closely with one or more associates in producing a work to which all who 
participate make the same kind of contribution (shared responsibility) or different contributions (mixed responsibility)” (Reitz, 2004, pp. 154-155). Because collaboration can foster mutual support and idea sharing, it offers a greater potential for learning than more solitary work (Echavarria, 2001). More importantly, a certain degree of collaboration is important in most librarians' work lives because all areas of librarianship are interrelated and depend on each other to achieve the purpose of serving the public (Lorenzen, 2006).

Networking as an activity to enhance one's career has also received relatively little attention in the literature. For the definition of networking, this paper uses "the art of developing contacts within a profession and using them to advance one's work and career” (Reitz, 2004, p.479). Librarians have long used associations, conventions, and more recently electronic discussion lists to make contacts, exchange ideas, and form collegial relationships that benefit their careers.

A substantial number of works address issues of concern to branch libraries and librarianship. However, most of these works are focused on the provision of services to users (e.g., reference, instruction, collection development). They either omit discussion of communication, collaboration, and networking all together, or mention them only briefly. Communications was the most-often addressed issue of the three.

The Association of College and Research Libraries’ Guidelines for Branch Libraries in Colleges and Universities includes a section on communications:

The goal of all communications should be to assure the effective operation of the branch within the service structure...A structure which encourages the exchange of information and expertise among branch libraries is also desirable. The establishment of connections with each other and with essential centralized services is paramount to effective and comprehensive branch library service (1990, Communications section, para. 1).

When librarians are scattered across branches, communication is generally more difficult than if all were at a main library (Tucker, 1995). At a main campus, librarians have more opportunities for conversation, both formal and casual. Having professional peers nearby can lead to innovation and progress; conversely, "being at a branch campus, one can often feel cut off psychologically as well as physically. Communications mistakes seem exaggerated, there are fewer people to bounce ideas off of, and it can sometimes make one feel lonely” (Jurkowski, 1997, p.157). As previously discussed, isolation may be felt at main campuses as well. Reiten and Fritts (2006) describe distance learning librarians "almost as solo librarians, divorced from their colleagues, even within an institution” (p. 398-399).

Because of their physical separation, branch librarians can feel a sense of isolation unless they make a conscious effort to "maintain good open communication channels" (Fritts, 1998). Jurkowski says that to break away from that sense of isolation, he began visiting the main library once a month (1997). In a 2005 survey of 169 branch librarians, 
75\% reported that travel was "an important method of communication between the campuses” (Brandt, Frederiksen, Schneider, \& Syrkin 2006, p.45). Jurkowski suggests talking to other librarians on the phone instead of e-mail because talking on the phone provides the opportunity for more communication than e-mail: people can "chat and try to keep up with new developments you might not hear about otherwise” (Jurkowski, 1997, p.158).

Collaboration is rarely mentioned in the branch literature, but it is essential to successful organizations. Members of successful organizations "must be willing to understand their own vested interest in the richness and complexity of both single and multiple collaborations” (Guard, 2005, p.90-91). In Brandt et al.'s 2006 survey, 55\% of branch libraries reported having relationships with local academic libraries outside their system (p. 49). Buck, Islam, and Syrkin (2006) also discussed the need for more "research that explores how collaborative relationships are initiated and by whom" (p.77).

Networking as an activity to enhance one's career is not discussed. However, participation in networks as a way of gaining networking opportunities is mentioned. Schneider's 2002 study considered the usefulness of regional library systems for academic libraries. "Most striking," Schneider wrote, "was the repeated statement that regional library systems offered a medium for human networking and a broader understanding of issues facing all libraries” (p.145). Another example of an organization fostering networking is the Hawaii Association of School Librarians' Collegial Assistance Network. This organization promotes mutual assistance and sharing of ideas, which in turn may lessen feelings of isolation (Echavarria, 2001).

The branch literature does name three groups that facilitate collaboration and networking among branch and regional librarians. The first is the Regional Campus Libraries Group, which meets at the American Library Association's Midwinter and Annual meetings and maintains an electronic discussion list, RCL-DG (http://www.tacoma. washington.edu/ library/rcl/). The second is Central Michigan University’s Off-Campus Library Services biennial Conference. An electronic discussion list, Off-Camp, is also associated with this group (http://listserv. utk.edu/archives/offcamp.html) (Lebowitz, 1997). Thirdly, ACRL’s Distance Learning Section (previously the Extended Campus Library Services Section) meets at the American Library Association's Midwinter and Annual meetings (Frederiksen, 2004).

Taken together, the existing literature on communication, collaboration, and networking in libraries points to the centrality and importance of these activities. Nonetheless, this existing literature relies mostly on anecdotes and folksy advice; quantitative studies on these topics are scarce.

\section{Methodology}

Issues surrounding networking and collaboration in multi-campus academic library systems are of great interest to many librarians, yet the literature is thin and 
studies touching on the topic are very few and far between. Therefore, the authors decided to administer an exploratory survey in an attempt to move beyond the sideways glances the topic usually attracts.

\section{Survey design}

In formulating the survey questions, the authors were influenced by many library research surveys, most notably that administered by Brandt et al. (2006) for their paper presented at the Twelfth Off-Campus Library Services Conference. In fact, the authors' project might be regarded as building directly on a small portion of Brandt et al. While the Brandt et al. study was wide-reaching (investigating branch and regional library issues such as staffing, communication, reporting, funding, services, collections, and more), the authors' study was intended to hone in on issues specifically related to communication, collaboration, and networking among librarians at multi-campus institutions. No other study to date has attempted to focus solely on these vital areas of concern.

The project was also influenced by a roundtable discussion at the 2007 ACRL National Conference in which the branch and regional campus librarians in attendance discussed issues of "isolation" and "inclusion" with relation to their interactions with "main” campus librarians (Bottorff, 2007). This study therefore also sought to examine this issue of "isolation," in particular to determine whether such feelings are truly prevalent in the library profession and whether they are in fact felt more keenly by branch/regional librarians than their main campus counterparts.

The survey questions were intended to garner information in five key areas: 1) The general characteristics of respondents; 2) communication behavior and frequency; 3) participation in committees; taskforces, and training; 4) networking behavior and frequency; and 5) collaboration behavior and frequency. All of the thirty-three survey questions and answer choices are reprinted in the Appendix.

The survey questions were formulated so as to be applicable to both branch/regional librarians and to main campus librarians, because the authors intentionally sought respondents from all different types of campuses (including "main" campuses) in order to allow for more meaningful comparisons and more easily quantifiable differences between the groups. This key decision added complexity to the administration and analysis of the survey, but the effort paid off in a very rich set of data that allowed for a greater range of comparison on this topic than had yet been attempted.

Before administering the survey instrument, the authors applied for Institutional Review Board (IRB) approval for the project, chose a software product to assist in the collection and analysis of data, and conducted a small pilot test. IRB approval was quickly obtained, as the study did not collect personally identifiable information on respondents. SurveyGold, a survey software product, was chosen to assist in the electronic collection and analysis of the data because it was available through the authors' institution and because it provided the necessary functionality for this project, 
including the ability to cross-tabulate between survey questions. The final survey questions were entered into the SurveyGold software and the resulting Web form was mounted to the Website of the authors' institution. Responses to the survey were retrieved from the SurveyGold server and then stored on the authors' computers for analysis.

Because input was sought from librarians in all types of campus configurations, the authors decided to request participation in the survey through recruitment messages posted to major, national electronic discussion lists for librarians in a wide variety of functional areas. Table 1 below lists the e-mail lists that were targeted in this study, along with the major functional area(s) covered by each list.

\section{[Ed.: insert Table 1 about here]}

Ultimately, a wide variety of respondents, from all types and sizes of libraries and all functional areas of librarianship, was obtained.

\section{Limitations}

An exploratory study of this type has some limitations. Respondents from electronic discussion lists are not truly randomized, and the actual response rate to the survey is not possible to determine since the number of subscribers to each list is not known and the message may have been forwarded to other lists or individual e-mail addresses without the authors' knowledge. This study also faced challenges related to terminology and definitions, as have nearly all previous studies on branch/regional libraries. There are simply too many different campus configurations in higher education, and the provision of library services across these campuses is so complex, that it is difficult to utilize terminology that will be understood by all respondents, even though the authors endeavored to overcome this problem whenever possible.

Nonetheless, despite these and other limitations, this study unquestionably achieved its primary goal of surveying a wide swath of the library population (from many functional areas and many different campus configurations) on communication, collaboration, and networking behavior, and the results offered abundant detail for analysis and discussion.

\section{Results}

\section{Profile of Respondents}

In all, 491 responses to the study were received. Consistent with IRB guidelines, participants were not required to respond to every question, though most participants did so: All questions received at least 458 responses, and most questions received more than 470 responses. 
The survey was targeted at academic librarians, particularly those at multi-campus institutions. Many of the first eight questions were designed primarily to quantify the background of respondents. The majority of respondents worked at a public institution (73\%), with the remaining respondents hailing from private institutions (25\%) or from “Other” institutions (2\%) with mixed funding models.

Most respondents worked at institutions where the doctorate degree is the highest degree granted (67\%), although responses also came from many other types of institutions: 16\% marked Master's, 13\% marked Associate, 3\% marked Baccalaureate, 2\% marked Other, and less than 1\% marked Technical/Certificate.

Respondents worked in a wide variety of professional statuses, ranging from those with faculty status and tenure (18\%) or seeking tenure (21\%) to those with faculty status but no option for tenure (22\%) or those without faculty status (28\%), as shown in Table 2 below. A sizable number of respondents (6\%) chose the "Other" option, the majority of these describing a faculty-like status such as "academic professional status" or a tenurelike situation such as "continuing appointment."

\section{[Ed.: insert Table 2 about here]}

Similarly, answers were diverse on the question inquiring about respondents' main/primary area(s) of professional responsibility. Participants were permitted to submit multiple responses to this question (percentages will add up to more than 100\%), and the data shows that most respondents indicated more than one major area of responsibility. While the largest responses came in the Reference (56\%), Instruction (47\%), Collection Management (32\%), Administration (21\%), and Cataloging (21\%) categories, significant numbers of responses were received in all major functional areas of librarianship, as presented in Table 3.

\section{[Ed.: insert Table 3 about here]}

Responses also varied widely on the question asking "How many degreed librarians (having a Master's in Library Science or an equivalent degree) work at your primary workplace?” The largest categories of responses came from those with 11-20 librarians (21\%) at the workplace, 6-10 librarians (21\%), and 3-5 librarians (17\%). See Table 4 below for the full range of responses to this question.

\section{[Ed.: insert Table 4 about here]}

Most respondents were from large institutions, with 50\% coming from parent institutions with more than 20,000 students, 22\% coming from institutions with between $10,000-20,000$ students, and 19\% coming from institutions with between 3,000-9,999 students. However, the results were more diverse when respondents were asked to indicate the number of students "on the campus you consider to be your primary workplace (i.e., where you consider your primary office to be)”: $28 \%$ marked 3,000- 
9,999 students, 24\% marked 10,000-20,000 students, 22\% marked 20,001+ students, 15\% marked 1,000-2,999 students, and 12\% marked 0-999 students.

One of the more crucial questions asked "At what type of library do you consider to be your primary workplace (i.e., where do you consider your primary office to be?)?" Responses to this question were eventually cross-tabulated with most other questions in the survey to determine differences among librarians at Main, Branch/Regional, and Decentralized libraries. Nearly half (44\%) of respondents said they work at a Main/Primary library of a centralized library system, but significant numbers also came from librarians in Decentralized systems (27\%), Branch/Regional campus librarians (17\%), and from the "Other" category (11\%). The "Other" responses were very diverse. The largest "Other" group indicated they worked at an institution in which there is only one library; although the survey was primarily designed to survey librarians at multicampus institutions, responses from this group were still valuable in establishing a baseline for issues of networking and collaboration, not to mention the subjective issue of "isolation" from other librarians. Other respondents in the "Other" category worked variously in situations such as a centralized technical services unit, an outsourcing agency, a freestanding information commons, a joint-use campus for two state universities, and other variations of semi-autonomous or decentralized settings. The responses to this question are summarized in Table 5 below.

\section{[Ed.: insert Table 5 about here]}

\section{Cross-Tabulations}

Most of the remaining questions were cross-tabulated with one or more other questions in order to more precisely analyze responses. For example, a question in the Communication section of the survey asked "How often do you go to other libraries in your system for library business?” While the overall response percentages to this question is useful and helps to establish a baseline for this question, the real point of the question was to find out whether librarians at different types of libraries (main, branch, decentralized, etc.) answer this question differently. Therefore, in addition to presenting the overall response percentages to this question, the responses to this question are also presented when cross-tabulated against the question about library type. In this case, for example, approximately $27 \%$ of all respondents said they Frequently or Very Frequently go to other libraries in their system for library business. However, by cross-tabulating this question with the library type question it is possible to see a more nuanced reality: only $18 \%$ of Main/Primary library respondents answered Frequently or Very Frequently to this question, compared to $50 \%$ of Branch/Regional library respondents. Clearly, the way in which librarians answer this question is affected to a large degree by the type of library they work at, thus displaying the value of using this cross-tabulation method.

\section{Communication}

The first major section of the survey sought to quantify the amount and frequency of communication (both direct and indirect) between librarians. 
When asked "How often do you go to other libraries in your system for library business?" significant differences were observed among respondents from the different library types. In essence, librarians at Branch/Regional libraries and librarians in Decentralized systems reported traveling to other libraries with a much greater frequency than did Main/Primary librarians (see Table 6 below).

\section{[Ed.: insert Table 6 about here]}

Similar differences were found when the question was turned around to ask "How often do other librarians in the system come to your workplace for library business?" In other words, Branch/Regional and Decentralized librarians reported getting visitors from other libraries for library business with less frequency than did their Main/Primary colleagues, as presented in Table 7 below.

\section{[Ed.: insert Table 7 about here]}

Respondents were asked to "estimate the distance (in miles) your workplace is from the closest other library in your system with which you regularly conduct library business." Distance from the next closest library in the system did not seem to be a factor in respondents' answers to the question on research and professional development opportunity or to the question on sense of isolation. However, distance did appear to be a slight factor in respondents' overall perception of networking and collaboration opportunity: As distance from the next closest library increased, some respondents reported having less opportunity for networking and collaboration. These results are summarized in Table 8 below.

\section{[Ed.: insert Table 8 about here]}

Method of communication among librarians at different libraries in the system was not found to be a significant factor in respondents' perception of opportunity for research or professional development, of opportunity for networking and collaboration, or of feeling isolated. Among all respondents, the most frequently used methods of communication were E-mail (98\%), Phone (84\%), and In-person visits (58\%) (multiple responses were allowed). Relatively few respondents reported using newer methods of communication such as Wikis (15\%), Blogs (14\%), Instant messaging (14\%), or Video conferencing (13\%), and only 17\% reported using Postal mail.

A correlation was found between "frequency of communication with librarians at other libraries in your system” and library type. Branch/Regional librarians and Decentralized librarians reported communicating with other librarians more frequently than did Main librarians, as shown in Table 9 below. For example, $71 \%$ of Branch librarians reported communicating Frequently or Very Frequently with other librarians in the system, compared to $56 \%$ of Decentralized librarians and 52\% of Main librarians.

\section{[Ed.: insert Table 9 about here]}


Those who communicate more frequently also tended to report feeling slightly less isolated. For example, among those who said they Rarely communicate with other system librarians, 36\% reported feeling isolated Frequently or Very Frequently; while among those who said they Frequently communicate with other system librarians, only $15 \%$ reported feeling isolated Frequently or Very Frequently.

\section{Committees, Taskforces, and Training}

The next section of the instrument surveyed respondents about participation in committee work, taskforces, and training.

Most respondents (61\%) reported participating in library system committees, taskforces, or workgroups Frequently or Very frequently, with Main respondents saying so with just slightly more frequency (67\%) than Branch/Regional (60\%) or Decentralized (55\%) librarians (see Table 10 below).

\section{[Ed.: insert Table 10 about here]}

Among all respondents, 68\% reported that their system Frequently or Very frequently includes representatives from more than one library on committees, taskforces, or workgroups.

In general, those who participate more frequently in committee work tended to report feeling slightly less isolated than those who participate less often. For example, among those who said they Frequently participate in committee work, only $8 \%$ said they Frequently feel isolated; whereas among those who said they Rarely participate in committee work, 29\% said they Frequently feel isolated.

Similarly, those who participate more frequently in committees tended to report having slightly more overall opportunity for networking and collaboration. Among those who said they Frequently participate in committee work, only $17 \%$ reported having less opportunity for networking and collaboration; by comparison, among those who said they Rarely participate in committee work, $37 \%$ reported having less opportunity for networking and collaboration.

Among all respondents, 71\% reported that the main barrier to participation on committees, taskforces, or workgroups (multiple responses allowed) is "lack of time due to other duties." The next highest responses were "lack of travel funding or transportation options" (24\%), "lack of administrative support" (16\%), and "lack of available technology solutions" (13\%). Only $14 \%$ felt that "shortage of committees or workgroups" was a significant barrier, and only $7 \%$ felt that "too much competition for committee assignments" is a factor.

Similarly, when asked "which area(s) of improvement below do you believe would most likely lead to better opportunities for participation on committees, taskforces, 
or workgroups within your library system?” the largest category of responses came in the "more time away from other duties" category (47\%). The next highest categories (multiple responses were allowed) were "more cross-training or exchange programs" (33\%), "more travel funding or transportation options" (30\%), "more technology solutions” (27\%), and “more support from administration” (27\%). The categories receiving the least support were "more social functions" (15\%) and "more committees or meetings” (9\%).

Regarding training opportunities, Main librarians reported participating in training sessions or workshops with greater frequency than Branch/Regional or Decentralized librarians. For example, 55\% of Main respondents said they Frequently or Very frequently participate in training sessions, compared to $43 \%$ of Branch/Regional respondents and only 30\% of Decentralized respondents.

\section{Networking}

The next section sought to survey respondents on their networking behavior. The authors used and supplied the following definition of networking to the survey participants: "The art of developing contacts within a profession and using them to advance one's work and career” (Reitz, 2004, p. 479).

Branch/Regional and Decentralized librarians reported having less opportunity for networking with colleagues within their system than Main librarians. For example, 57\% of Main respondents said they Frequently or Very frequently have networking opportunities with colleagues within the system, compared to 49\% of Branch/Regional respondents and 38\% of Decentralized respondents. See Table 11 below for more detail.

\section{[Ed.: insert Table 11 about here]}

When asked about networking opportunities with colleagues outside their system, however, there was no significant difference in the responses by library type:

Approximately 32\% of all respondents said they Frequently or Very frequently have such opportunities with librarians outside their own system.

When asked about barriers to networking with colleagues within the system (multiple responses were allowed), among all respondents "lack of time due to other duties" was again the largest category (73\%). The next highest categories were "lack of travel funding or transportation options” (27\%), "lack of social functions” (26\%), "lack of cross-training or exchange programs" (21\%), and "lack of support from administration" (20\%). Only 14\% of respondents felt that "lack of technology solutions" is a significant barrier, and only $12 \%$ checked the option for "shortage of committees or meetings.”

Similarly, when asked which area(s) of improvement would most likely lead to better opportunities for networking within the system, among all respondents the highest category was "more time away from regular duties" (56\%), followed by "more cross- 
training or exchange programs” (32\%), "more social functions” (32\%), "more travel funding or transportation options" (27\%), and "more support from administration” (26\%). The categories receiving the least support were "more technology solutions" (22\%) and "more committees or meetings" (12\%).

\section{Collaboration}

The next section surveyed respondents on their behavior regarding collaboration with other librarians. The authors used and supplied the following definition of collaboration to the survey participants: "To work closely with one or more associates in producing a work to which all who participate have shared or mixed responsibility" (adapted from Reitz, 2004, p. 154-155).

When asked "How often would you say you collaborate with colleagues at other libraries within your own library system on day-to-day tasks or responsibilities?” respondents' answers were varied. The three largest groups of aggregate responses were Occasionally (28\%), Rarely (27\%), and Frequently (23\%), followed by Never (12\%) and Very Frequently (9\%). The type of library at which participants worked did not appear to play a significant role in influencing responses for this question.

A majority of respondents reported collaborating with colleagues at other libraries within their own library system on service, research, or professional development activities either Occasionally (35\%) or Rarely (32\%). Other respondents indicated that they Never (19\%), Frequently (11\%) or Very Frequently (3\%) collaborated with internal colleagues for professional development activities such as research articles, conference presentations, poster sessions, and outside committee work. Aggregate data revealed similar results in regards to frequency of collaboration with colleagues outside the respondents' library system for service, research, or professional development activities.

Perceived opportunity in terms of professional development activities seemed to be associated with such factors as the type of library, the number of degreed librarians in the primary workplace, and the frequency of communication with other librarians in their library system. Slightly more of the respondents who perceived that they had less

opportunity than their colleagues hailed from Branch/Regional campus libraries (27\%) or Decentralized libraries (23\%) than Main campus libraries (15\%) or Other types of libraries (8\%). Of more significance was the fact that over half of respondents whose primary workplace had only one (56\%) or two (52\%) degreed librarians perceived that they had less opportunity than most of their colleagues in terms of professional development activities, as shown in Table 12 below.

\section{[Ed.: insert Table 12 about here]}

Most respondents indicated having "about the same" amount of opportunity as their colleagues for research and professional development, regardless of their frequency of communication. However, those who answered that they communicated more frequently with other librarians in their library system tended to report having slightly 
more opportunity for research and professional development. For example, 24\% of respondents who perceived that they communicate on a Frequent basis and $22 \%$ who communicated on a Very Frequent basis felt that they had more opportunity than most of their colleagues in terms of research articles, conference presentations, poster sessions, and outside committee work, as compared to those who communicated Occasionally (13\%), Rarely (10\%), or Never (14\%).

Method of communication was not a major factor in perception of opportunity for research and professional development, although those who admitted using newer methods (such as blogs, IM, and wikis) did report having slightly more research and professional development opportunity.

A majority of respondents perceived that they had about the same level of professional development opportunities as most of their colleagues regardless of distance from the next closest other library in their system.

Another factor the authors sought to measure was the respondents' perceived overall opportunity in terms of networking and collaboration. Of those who reported having less opportunity for networking and collaboration, a higher percentage of respondents came from Branch/Regional campus libraries (29\%) and Decentralized libraries (23\%) than from Main libraries (15\%), as seen in Table 13 below.

\section{[Ed.: insert Table 13 about here]}

A relationship was found to exist between perceived networking and collaboration opportunity and the number of degreed librarians in the primary workplace. After crosstabulation, data revealed that $62 \%$ of respondents working in libraries staffed with only one degreed librarian and $47 \%$ of respondents working in libraries staffed with only two degreed librarians felt they had less opportunity in terms of networking and collaboration, as detailed in Table 14 below.

\section{[Ed.: insert Table 14 about here]}

Another issue this survey aimed to investigate was participants' sense of isolation in different library settings. Perceived isolation appeared to be influenced by several factors including type of library, number of librarians at the primary library, and distance from other libraries. Branch/Regional librarians (27\%) and Decentralized librarians (22\%) reported higher figures of Frequent or Very Frequent isolation than their Main library counterparts (14\%).

The number of degreed librarians at the primary workplace seems to be strongly correlated with perceived isolation. With the exception of libraries with over 50 librarians, the fewer the number of librarians at a location, the more likely the respondent was to report feeling isolated, as presented in Table 15 below.

\section{[Ed.: insert Table 15 about here]}


Distance from the next closest library appeared to be a major factor in feeling isolated from colleagues within one's own library system only for participants at extremely remote library locations. Thirty seven percent of respondents whose primary workplace is greater than 100 miles from the nearest library in the system reported feeling isolated Frequently or Very Frequently, as compared to other distances, such as 05 miles (21\%), 6-10 miles (16\%), 11-20 miles (23\%), 26-50 miles (16\%), or 50-100 miles (20\%).

In two related questions, respondents were asked to identify perceived "barriers to collaboration with colleagues within your library system" and highlight areas they felt "would most likely lead to better opportunities for collaborating with colleagues." Respondents could specify more than one answer in both questions. The most prevelant barrier to collaboration, identified by more than two-thirds (69\%) of all respondents, regardless of library type, was "lack of time due to other duties." Other percieved barriers included "lack of support from administration" (23\%), "lack of cross-training or exchange programs" (22\%), "lack of travel funding of transportation options" (21\%), "lack of social functions" (19\%), "lack of technology solutions" (13\%), and "shortage of committees or meetings" (11\%).

Preferred areas of improvement appeared to follow suit with the barriers identified above. "More time away from regular duties" (63\%) was the highest reported area that respondents felt would most likely lead to better opportunities for collaborating with colleagues. Other areas of potential improvement identified were "more crosstraining or exchange programs" (33\%), "more support from administration” (30\%), "more travel funding or transportation options" (24\%), "more social functions" (24\%), "more technology solutions" (18\%), and "more committees or meetings" (11\%).

\section{Comments}

The final question on the survey allowed participants to submit "any final comments about the topics covered in this survey." More than 115 respondents (nearly one-quarter of those who took the survey) submitted additional comments, providing further indication that this is a topic of great interest and passion to many librarians. Several of the more insightful or useful comments will be quoted or touched upon in the Discussion section below.

\section{Discussion}

This study represents a leap forward in the library profession's understanding of issues related to networking and collaboration among academic librarians at multicampus institutions. Thus far, the library literature has devoted little attention to networking and collaboration of any kind, let alone to the more complex channels of communication and sharing that occur in library systems that have spread beyond a main/primary library. Ultimately, the results of this study, combined with participant comments, may point the way towards better models of communication and collaboration among librarians of all types. 
The results reveal several important areas that deserve further attention.

\section{Library Type}

The results indicate that library type does seem to be a factor in how frequently some librarians participate in activities such as travel to other libraries, committee work, training, research, professional development, networking, and collaboration. In the end, there was a lot of commonality among respondents of all types, with the data lumping towards the middle point on many questions - in other words, behaviors and perceptions of librarians at the various types of libraries were more alike than they were different.

There were, however, key differences in some areas. In general, a higher percentage of Main campus librarians reported traveling less frequently, communicating less frequently with librarians at other libraries, and participating more frequently in committee work and training. A higher percentage of Branch librarians reported traveling more often, communicating more often, feeling isolated more frequently, and having less overall opportunity for committee work, training, research, networking, and collaboration. Decentralized librarians aligned closely with Branch librarians in most categories, although they tended to report having even less opportunity than Branch librarians for training, networking, and collaboration.

Although the hard numbers fail to illuminate the reasons behind these differences, many participants attempted to do so in their comments. Many branch/regional librarians pointed to possible reasons for their perceived lack of opportunities. One regional librarian stated: "It's definitely a lot harder for regional/branch campus librarians to collaborate and network with our colleagues. The main campus library has lots of social activities, but it's very hard for those of us from regional campuses to participate as it involves travel and time away from work." One branch librarian pointed to both tangible and intangible factors:

I don't think we can discount the difference it makes when we're not physically in the same place with most of our colleagues. We miss out on the "watercooler" conversations that lead to collaborative relationships. Technology helps on some level, but it's not a total replacement for the day-to-day relationships built in a workplace. Geographic distance matters too.....Needless to say, few [main campus librarians] make the trip in our direction.

One librarian who used to work at a regional campus before moving to the main campus admitted, "On a main campus now, I do like the nearby collegiality, shared campus culture and environment, the impromptu brainstorming and access to a wider variety of resources and opportunities to collaborate with faculty outside the library.”

A number of branch librarians also expressed the feeling that main campus librarians frequently "forget" about other campuses or do not "think about... other campus libraries unless they need help or money.” Similarly, many respondents alluded 
to a perception that many main campus librarians are reluctant to travel to other campuses or even, in some cases, to include branch/regional librarians in meetings via teleconferencing equipment.

\section{Number of Librarians at Primary Workplace}

Another key finding of this study is that the number of other librarians at one's primary workplace appears to be a factor in perception of isolation and in perceived opportunity for networking and collaboration. Generally speaking, the fewer the number of librarians at the primary workplace, the more likely the respondent was to report feeling a sense of isolation or to report having less opportunity for networking and collaboration. This correlation was particularly strong among librarians at workplaces with fewer than three librarians, or fewer than six librarians for some questions.

One banch librarian alluded to the possibility that librarians in smaller libraries may be hampered in their research and professional development activities by the need to take on more (or more varied) job responsibilities: "Something I feel needs to be examined more thoroughly is the difference in opportunities in smaller branch libraries and increased duties, and yet, we are expected to produce similar levels of service and research for tenure.”

Many other respondents expressed the idea that "technology is not always a substitute for face to face interaction” even under the best of circumstances, while one off-campus librarian commented that "networking by phone or web conferencing helps but on-campus librarians don't always plan to include me, set up phone, connect via NetMeeting, and send handouts." Another librarian said, "In the last year or so we have done much more with IMing and web cam, but I still feel very separate from the main branch.” Indeed, twice as many Branch librarians (27\%) reported that they Frequently or Very Frequently "feel a sense of isolation from colleagues," as compared to Main librarians (14\%).

\section{Distance and Communication}

Several other factors were identified in the results or by participant comments. Distance from the next closest library in the system was a small factor in feelings of isolation and in overall perception of networking and collaboration opportunity, though primarily for librarians who are more than 100 miles away from the next closest library in the system - for whom face-to-face meetings with system colleagues is rare and for whom geographic isolation is very real.

Neither frequency of communication nor method of communication was identified as a major factor in the issues examined by this study, although those who reported communicating more frequently did tend to report having slightly more opportunity for networking and collaboration, as did those who reported adopting newer forms of communication (such as blogs, IM, and wikis). The differences in these 
categories were not nearly as substantial, however, as those related to factors such as library type or the number of librarians at the primary workplace.

\section{Administrative Role}

Many respondents commented on the role of library administrators in improving networking and collaboration among system librarians. They frequently pointed to the need for more administrative support and stronger leadership on these issues. For example, one librarian said:

I believe that the greatest barrier to cross-campus collaboration and networking is library administrators who do not support their staff. One library administrator in our system forbids her staff members from participating in professional associations on work time! Most library directors in our system do not belong to professional associations, attend conferences, or publish, nor do they encourage their staffs to do so.

Several respondents alluded to administrative issues and organizational barriers by mentioning disadvantaged funding situations for branch/regional libraries in the system. For example, one regional campus librarian noted that "Competition for funds is intense between campuses... at this point, the strain of having too much to do and not enough funding on our campus has created an IMPOSSIBLE situation for research and promotion, as well as decimating our materials budget.” Another branch librarian said, "The main campus has tons of money for all kinds of things.... [whereas] our budget is sadly lacking for travel, etc., making it necessary for librarians to pay out of pocket nearly all the time.”

This animosity among campuses or branches_and administration's role in creating or breaking down such barriers - was mentioned by several other respondents. One paricipant noted that "we used to have much better relations with the other campus librarians but a few individuals with administrative power have undermined that collegiality with some of their decisions and attitudes towards the other campus libraries." And another asserted, "If someone could come up with a 'fix-it' to the real or perceived THEM vs. US mentality, that would go a long way to address geographical challenges.”

Abolishing the "them vs. us" mentality that is perceived to exist at some institutions may be crucial in overcoming feelings of isolation and in providing better opportunities for networking and collaboration. The means for doing so are likely institution-specific, but the results of this study suggest that many librarians are interested in playing a part if administrators are willing to have such discussions. 


\section{Lack of Time Due to Other Duties}

One factor noted by librarians of all types was "lack of time due to other duties." Indeed, survey respondents of all types consistently alluded to lack of time as a major barrier to greater participation in everything from training to committee work to research to networking and collaboration.

As one respondent put it, "We all wear many hats and are gaining more responsibilities all of the time. There is little time to do much besides provide good basic services.” Another respondent said, “Time is the biggest problem for me. Even though we're a very large library, we're stretched painfully thin. I have two full-time jobs within the library.... I regularly work 50 hours a week or more and much of my days off/weekend time is spent on doing library work at home." Another lamented: "I have too much to do, so I lack time for research, service, networking, publishing, etc.” Indeed, when asked about job responsibilities, the average respondent checked three "major/primary" areas of responsibility, and many librarians undoubtedly have several secondary areas of responsibility as well.

A severe lack of time and the need to balance ever-increasing job responsibilities is pervasive throughout academic librarianship, and devising solutions that address these issues will not be easy. Results and participant comments to this study do indicate that many librarians may be satisfied to start with small, incremental changes that would allow more release time from day-to-day duties for the purpose of pursuing activities such as research, professional development, networking, and collaboration: These small amounts of time may pay off later in terms of increased productivity and collaboration.

\section{Conclusion}

\section{Areas for Further Research}

There is ample room for further research on the topics addressed by this study. More focused studies, investigating issues of networking and collaboration among particular types of libraries (decentralized systems, for example, seem to have some unique challenges and issues) might reveal more nuanced understanding of the topics involved.

This study found that library type and number of librarians at the primary workplace are important factors related to these topics, but future studies may wish to consider other areas, such as those identified in some of the respondent comments to this study, for example:

- Personality type (e.g., introverted vs. extroverted)

- Administrative reorganization and the addition or removal of layers of bureaucracy

- Changing standards for promotion and tenure in academic libraries

- Generational diversity 
- Unionization

- Length of time in the profession

Additional research also needs to be conducted to more clearly identify solutions and strategies for coping with feelings of isolation and for improving networking and collaboration opportunities.

\section{Branching Out: Towards Better Communication \& Collaboration}

Although the primary purpose of this study was investigative, the results and respondent comments do begin to point the way towards some solutions and suggestions for better networking and collaboration among librarians.

Returning to the questions posed in the Introduction: Do librarians at branch locations frequently feel "isolated" from their main campus colleagues? In this study, the majority of respondents from all library types reported feeling isolated Never, Rarely, or only Occasionally. However, there were a significant number of respondents, particularly among Branch/Regional librarians, who consistently expressed notions of feeling isolated from colleagues. For example, twice as many Branch librarians (as compared to Main librarians) indicated that they Frequently or Very Frequently feel isolated, and many Branch librarian comments spoke to aspects of this issue. On the other hand, it is important to note that approximately one out of seven Main librarians reported feeling isolated Frequently or Very Frequently as well-in other words, this issue of collegial isolation is more complex than can be explained simply by library type or distance. In any case, it is clear that more systems need to have conversations about and take actions to address perceptions of system-wide issues such as inclusion, communication, and collaboration.

Are librarians within multi-campus institutions utilizing new technology to improve channels of communication and collaboration? Most respondents to this study indicated that they rely primarily upon traditional methods of communication, such as email, phone, and in-person visits. Newer forms of communication such as blogs, instant messaging, video conferencing, and wikis received far lower rates of usage. Individual librarians who reported using these newer methods of communication did report having slightly more opportunity for research, networking, and collaboration. It is not clear whether these individual efforts to adopt more methods of communication actually translate into significantly more (or better) opportunities for communication and collaboration. Additional research may need to be conducted to determine whether library systems that adopt some of these alternative means of communication tend to have significantly more (or better) internal communication, collaboration, and networking channels.

Do all librarians within multi-campus institutions have roughly equal opportunities for collaboration, networking, and professional development activities? A majority of all respondents felt their opportunities were relatively equal to those of their colleagues, although sizable minorities disagreed. For example, higher percentages of 
librarians at branch locations, librarians in decentralized systems, and librarians with very few colleagues at their primary workplace reported having less overall opportunity than librarians at main/primary campus libraries. Among all factors considered in this study, library type and number of librarians at the primary workplace were the most significant factors contributing to reported levels of opportunity for collaboration, networking, and professional development activities.

Many respondents suggested that initiatives to improve collaboration, networking, and professional development among system librarians should come from the top down. Library administrators "need to make intercampus relations a priority," wrote one respondent; another mentioned the need for a "positive cultural shift to encourage system communication.” Indeed, several participants alluded to the need for rewards and incentives to promote better collaboration and communication. One librarian wrote:

Administrators have to create a culture that rewards interdepartmental and interlibrary cooperation, collaboration, and coordination efforts or it just won't be a priority with the rank and file. It takes effort to do this well and all effort needs to be reinforced in some way that translates into recognition or rewards by the organizational leaders.

Another respondent similarly alluded to the need for more unifying efforts on the part of library administrators:

In all, whether networking or collaboration, administrators must agree upon the necessity of allowing time and funds for all of us to participate in activities away from our own campus. A concerted effort to unite us and grant opportunities to discuss and solve problems with other institutions in our own system and outside of our own system must be undertaken. Isolation is absolutely a very real problem even though we are a part of a much larger organization. The leadership must recognize the need!

On the other hand, the need to provide time and funds for frontline librarians to become more expansive and inclusive in their approach to working with colleagues largely clashes with the reality of reduced budgets, smaller staffs, and increasingly more difficult and time-consuming job assignments.

Clearly, the way forward for the profession - the way towards better collaboration and communication among librarians in multi-campus academic institutions-will require individual effort, strong leadership, creative solutions, and additional research and investigation. 


\section{References}

Association of College and Research Libraries. (1990, June 26). Guidelines for branch libraries in colleges and universities. In Standards \& Guidelines. Retrieved November 28, 2007 from http://www.ala. org/ala/acrl/acrlstandards/guidelinesbranch.cfm

Bottorff, T. (2007, March). Survive on exile island: How branch, regional, and extended campus librarians can better connect \& collaborate with main campus colleagues. Roundtable discussion presented at the annual meeting of the Association of College and Research Libraries, Baltimore, MD.

Brandt, J., Frederiksen, L., Schneider, T., \& Syrkin, D. (2006). The face of regional campus libraries and librarianship. Journal of Library Administration, 45(1/2), 37-61.

Buck, S., Islam, R., \& Syrkin, D. (2006). Collaboration for distance information literacy instruction: Do current trends reflect best practices. In J.A. Garrison (Ed.), The Twelfth Off-Campus Library Services Conference Proceedings (pp. 63-79). New York: Haworth Information Press.

Crockett, C. (2000). Reconfiguring the branch library for a more virtual future. Library Administration \& Management, 14(4), 191-196. Retrieved from the WilsonWeb database.

Echavarria, T. (2001). Collegiality and the environmental climate of the library. Alki, 17(3), 22-24.

Frederiksen, L. (2004). Beyond the extended campus library: A brief history of the Distance Learning Section. Journal of Library and Information Services in Distance Learning, 1(1), 45-54.

Fritts, J. (1998). Administrative structures for extended campus library services: A survey of institutional operations. In P.S. Thomas \& M. Jones (Comps.), The Eighth OffCampus Library Services Conference Proceedings (pp. 146-154). Mt. Pleasant: Central Michigan University.

Guard, R. (2005). Musings on collaboration and vested interest. The Journal of Academic Librarianship, 31(2), 89-91.

Jurkowski, O. L. (1997). Big fish in a little pond: Autonomy in an academic branch library. Illinois Libraries, 79(4). Retrieved December 10, 2007, from the Illinois Periodicals Online Web site: http://www.lib.niu.edu/ipo/1997/il9704157.html 
Lebowitz, G. (1997). Library services to distant students: An equity issue. The Journal of Academic Librarianship, 23(4), 303-308. Retrieved from the Science Direct database.

Lorenzen, M. (2006). Collegiality and the academic library. Electronic Journal of Academic and Special Librarianship, 7(2). Retrieved October 28, 2007, from http://southernlibrarianship.icaap. org/content/v07n02/lorenzen_m01.htm

Reiten, B. A., \& Fritts, F. (2006). Distance learning librarianship research over time: Changes and the core literature. In J.A. Garrison (Ed.), The Twelfth Off-Campus Library Services Conference Proceedings (pp. 397-410). New York: Haworth Information Press.

Reitz, J.M. (2004). Dictionary for library and information science. Westport, CT: Libraries Unlimited.

Schneider, T. M. (2002). Academic libraries and regional library systems: How do they stand today? The Journal of Academic Librarianship, 28(3), 141-146. Retrieved from the Science Direct database.

Tucker, J. (1996). Management issues for off-campus library delivery services, particularly in a multicampus environment. In C.J. Jacob (Ed.), The Seventh OffCampus Library Services Conference Proceedings (pp. 363-373). Mt. Pleasant: Central Michigan University. 


\section{Appendix}

\section{Networking and Collaboration Survey}

1. Please indicate the primary funding status of your parent institution:

Public Private Other

2. Please indicate the highest level of degree granted by your parent institution:

Technical/Certificate Associate Baccalaureate Master's Doctorate Other

3. What is the approximate number of students at your institution (including all campuses)?

0-999 1,000-2,999 3,000-9,999 10,000-20,000 More than 20,000

4. What is the approximate number of students on the campus you consider to be your primary workplace (i.e., where you consider your primary office to be?)

0-999 1,000-2,999 3,000-9,999 10,000-20,000 More than 20,000

5. What is your status?

Librarian with faculty status-tenured Librarian with faculty status-tenured-track but not yet tenured Librarian with faculty status-non tenure-earning Librarian without faculty status Adjunct librarian Library paraprofessional/Support staff Other

6. What is/are your main/primary area(s) of responsibility? (Select all that apply.)

Acquisitions Administration Cataloging Circulation Collection Management Government Documents Interlibrary Loan Instruction Reference Special Collections/ Archives/Rare Books Systems/Web Design/Elec. Resources Technical Services Other

7. At what type of library do you consider to be your primary workplace (i.e., where do you consider your primary office to be?)?

Main/Primary library of a centralized multi-library system (i.e., in which there is one main/primary library and one or more branch/regional libraries)

Branch/Regional library of a centralized multi-library system (i.e., in which there is one main/primary library and one or more branch/regional libraries)

A library in a decentralized multi-library system (i.e., in which there are several more-or-less autonomous libraries of more-or-less similar size/scope)

Other

8. How many degreed librarians (having a Master's in Library Science or an equivalent degree) work at your primary workplace?

$$
\begin{array}{llllllll}
0 & 1 & 2 & 3-5 & 6-10 & 11-20 & 21-35 & 35-50
\end{array} \text { More than } 50
$$

\section{Communication}

9. How often do you go to other libraries in your system for library business?

Never Rarely Occasionally Frequently Very frequently

10. How often do other librarians in the system come to your workplace for library business?

Never Rarely Occasionally Frequently Very frequently

11. Please estimate the distance (in miles) your workplace is from the closest other library in your system with which you regularly conduct library business?
0-5 6-10 11-25 26-50 51-100 More than $100 \quad$ Not applicable

12. What are the usual methods of communication among librarians at different libraries in your system? (Check all that apply.)

Blog E-mail In-person visit Instant Message (IM) Phone Postal mail

Video conference Wiki Other 
13. What is your frequency of communication with librarians at other libraries in your system? Never Rarely Occasionally Frequently Very frequently

Committees, Taskforces, and Training

14. How often do you participate in your library system's committees, taskforces, or workgroups? Never Rarely Occasionally Frequently Very frequently

15. How often do system committees, taskforces, or workgroups include representatives from more than one library within your system?
Never Rarely Occasionally
Frequently Very frequently

16. How often do you participate in your library system's training sessions or training workshops? Never Rarely Occasionally Frequently Very frequently

17. Which of the following (if any) listed below do you perceive are barriers to participation on committees, taskforces, or workgroups within your library system? (Select all that apply.)

Shortage of committee or workgroup assignments Too much competition for committee or workgroup assignments Lack of time due to other duties Lack of support from admin. Lack of travel funding or transportation options Lack of available technology solutions (e.g., blogs, IM, videoconference equipment, wikis, etc.) Not applicable Other

18. Which area(s) of improvement below do you believe would most likely lead to better opportunities for participation on committees, taskforces, or workgroups within your library system? (Check all that apply.)

More committees or meetings More cross-training or exchange programs

More social functions More time away from regular duties More support from admin. More travel funding or transportation options More technology solutions N/A Other

Networking. For this section, please keep in mind Joan M. Reitz's definition of networking: "The art of developing contacts within a profession and using them to advance one's work and career." (ODLIS: Online Dictionary of Library and Information Science)

19. How often would you say you have networking opportunities with colleagues within your own library system?

Never Rarely Occasionally Frequently Very frequently

20. How often would you say you have networking opportunities with colleagues outside of your own library system?

Never Rarely Occasionally Frequently Very frequently

21. Which of the following (if any) listed below do you perceive are barriers to networking with colleagues within your library system? (Select all that apply.)

Shortage of committees or meetings Lack of cross-training or exchange programs Lack of social functions Lack of time due to other duties Lack of support from admin. Lack of travel funding of transportation options Lack of technology solutions N/A Other

22. Which area(s) of improvement below do you believe would most likely lead to better opportunities for networking within your library system? (Select all that apply.)

More committees or meetings More cross-training or exchange programs More social functions More time away from regular duties More support from administration More travel funding or transportation options More technology solutions (e.g., blogs, IM, videoconference equipment, wikis, etc.) Not applicable Other

Collaboration. For these questions, please keep in mind the following definition of collaborate (adapted from Joan M. Reitz): "to work closely with one or more associates in producing a work to which all who participate have shared or mixed responsibility." (ODLIS: Online Dict. for Library and Info. Science) 
23. How often would you say you collaborate with colleagues at other libraries within your own library system on day-to-day tasks or responsibilities?

Never Rarely Occasionally Frequently Very frequently

24. How often would you say you collaborate with colleagues at other libraries within your own library system on service, research, or professional development activities (e.g., research articles, conference presentations, poster sessions, outside committee work, etc.)?

Never Rarely Occasionally Frequently Very frequently

25. How often would you say you collaborate with colleagues outside your own library system on service, research, or professional development activities (e.g., research articles, conference presentations, poster sessions, outside committee work, etc.)?

Never Rarely Occasionally Frequently Very frequently

26. Thinking in terms of professional development activities (e.g., research articles, conference presentations, poster sessions, outside committee work, etc.), do you believe you have:

More opportunity than most of your colleagues About the same opportunity as most of your colleagues Less opportunity than most of your colleagues Not applicable Other

27. How often do you feel a sense of isolation from colleagues within your own library system?

Never Rarely Occasionally Frequently Very frequently

28. Which of the following (if any) listed below do you perceive are barriers to collaboration with colleagues within your library system? (Select all that apply.)

Shortages of committees or meetings Lack of cross-training or exchange programs Lack of social functions Lack of time due to other duties Lack of support from administration Lack of travel funding or transportation options Lack of technology solutions (e.g., blogs, IM, videoconference equipment, wikis, etc.) Not applicable Other

29. Which area(s) of improvement below do you believe would most likely lead to better opportunities for collaborating with colleagues within your library system? (Select all that apply.)

More committees or meetings More cross-training or exchange programs More social

functions More time away from regular duties More support from administration More travel funding of transportation options More technology solutions (e.g., blogs, IM, videoconference equipment, wikis, etc.) Not applicable Other

30. Do librarians of equal rank within your system earn similar salaries, regardless of location?

Yes No-librarians at the main/primary library make more No-librarians at the branch/ regional libraries make more No-each location has a different salary scale N/A Other

31. Do librarians at all locations within your library system undergo the same process of review for promotion and tenure decisions?

Yes No-librarians at main/primary library undergo a different process than branch/regional librarians No-each location has a different process Not applicable Other

32. Thinking in terms of networking and collaboration, overall do you believe you have:

More opportunity than most of your colleagues About the same opportunity as most of your colleagues Less opportunity than most of your colleagues Not applicable Other

33. Do you have any final comments about the topics covered in this survey?

\section{Acknowledgements}

A number of the questions above were adapted from the following article: Brandt, J., Frederiksen L., Schneider T., \& Syrkin, D. (2006). The face of regional campus libraries and librarianship. Journal of Library Administration. 45(1/2), 37-61. 


\section{Tables}

\section{Table 1}

Email Lists Targeted for Survey Recruitment

\begin{tabular}{ll} 
Email list & Functional area of librarianship \\
\hline Archives \& Archivists (A\&A) List & Archives \\
Autocat & Cataloging \\
Bus-Lib & Business librarianship \\
CIRCPLUS & Circulation \\
EBSS (ACRL/EBSS Section) & Education \& behavioral sciences librarianship \\
GOVDOC-L & Government documents \\
Hospitality-Lib & Hospitality librarianship \\
ILI-L & Instruction and information literacy \\
ILL-L & Interlibrary loan \\
ILLIAD-L & Interlibrary loan \\
LIBADMIN & Administration \\
Liblicense-L & Electronic resources licensing \\
NMRT & New members roundtable \\
OCLC-CAT & Cataloging \\
Off-Camp & Off-campus library services \\
RCL-DG & Regional campus library services \\
RUSA & Reference \\
ULS-L (ACRL/Univ. Libraries Section) & University libraries \\
Web4Lib & Web systems in libraries \\
\hline
\end{tabular}

\section{Table 2}

Professional Status of Respondents

\begin{tabular}{lc} 
Professional status & Respondents (n=491) \\
\hline Faculty status and tenured & $18 \%$ \\
Faculty status, tenure-earning, but not yet tenured & $21 \%$ \\
Faculty status, non-tenure earning & $22 \%$ \\
Without faculty status & $28 \%$ \\
Adjunct librarian & $1 \%$ \\
Paraprofessional/support staff & $4 \%$ \\
Other & $6 \%$ \\
\hline
\end{tabular}


Table 3

Main/primary Area(s) of Responsibility of Respondents

\begin{tabular}{lc} 
Area(s) of responsibility (multiple responses allowed) & Respondents ( $=491)$ \\
\hline Acquisitions & $13 \%$ \\
Administration & $21 \%$ \\
Cataloging & $21 \%$ \\
Circulation & $15 \%$ \\
Collection management & $32 \%$ \\
Government documents & $8 \%$ \\
Interlibrary loan & $15 \%$ \\
Instruction & $47 \%$ \\
Reference & $56 \%$ \\
Special collections/Archives/Rare books & $7 \%$ \\
Systems/Web design/Electronic resources & $18 \%$ \\
Technical services & $12 \%$ \\
Other & $14 \%$ \\
\hline
\end{tabular}

\section{Table 4}

Number of Librarians at Primary Workplace

\begin{tabular}{cc} 
Number of Librarians & Respondents $(\mathrm{n}=489)$ \\
\hline 0 & $1 \%$ \\
1 & $5 \%$ \\
2 & $7 \%$ \\
$3-5$ & $17 \%$ \\
$6-10$ & $21 \%$ \\
$11-20$ & $21 \%$ \\
$21-35$ & $13 \%$ \\
$36-50$ & $8 \%$ \\
$51+$ & $8 \%$ \\
\hline
\end{tabular}

\section{Table 5}

\section{Library Type}

Type of library at primary workplace

Respondents $(\mathrm{n}=486)$

Main/Primary library of a centralized system

$44 \%$

Branch/Regional library of a centralized system

$17 \%$

Library in a decentralized multi-library system

$27 \%$

Other

$11 \%$ 


\section{Table 6}

Type of Library at Primary Workplace Cross Tabulated with

Perceived Frequency Respondents Travel to Other Locations in System for Library Business

\begin{tabular}{lcccrr} 
& $\begin{array}{c}\text { All respondents } \\
(\mathrm{n}=484)\end{array}$ & $\begin{array}{c}\text { Main campus } \\
(\mathrm{n}=215)\end{array}$ & $\begin{array}{c}\text { Branch campus } \\
(\mathrm{n}=84)\end{array}$ & $\begin{array}{c}\text { Decentralized } \\
(\mathrm{n}=132)\end{array}$ & $\begin{array}{c}\text { Other } \\
(\mathrm{n}=50)\end{array}$ \\
\hline Never & $8 \%$ & $12 \%$ & $1 \%$ & $3 \%$ & $16 \%$ \\
Rarely & $29 \%$ & $37 \%$ & $18 \%$ & $25 \%$ & $26 \%$ \\
Occasionally & $35 \%$ & $33 \%$ & $30 \%$ & $42 \%$ & $34 \%$ \\
Frequently & $21 \%$ & $14 \%$ & $39 \%$ & $24 \%$ & $18 \%$ \\
Very frequently & $6 \%$ & $4 \%$ & $12 \%$ & $6 \%$ & $6 \%$ \\
\hline
\end{tabular}

\section{Table 7}

Type of Library at Primary Workplace Cross Tabulated with Perceived Frequency Librarians from Other Locations in System Travel to Respondents' Primary Workplace for Library Business

\begin{tabular}{lccccc}
\hline & $\begin{array}{c}\text { All respondents } \\
(\mathrm{n}=482)\end{array}$ & $\begin{array}{c}\text { Main campus } \\
(\mathrm{n}=213)\end{array}$ & $\begin{array}{c}\text { Branch campus } \\
(\mathrm{n}=84)\end{array}$ & $\begin{array}{c}\text { Decentralized } \\
(\mathrm{n}=132)\end{array}$ & $\begin{array}{c}\text { Other } \\
(\mathrm{n}=50)\end{array}$ \\
\hline Never & $7 \%$ & $4 \%$ & $8 \%$ & $7 \%$ & $20 \%$ \\
Rarely & $31 \%$ & $16 \%$ & $45 \%$ & $41 \%$ & $42 \%$ \\
Occasionally & $34 \%$ & $38 \%$ & $36 \%$ & $31 \%$ & $22 \%$ \\
Frequently & $23 \%$ & $34 \%$ & $10 \%$ & $17 \%$ & $16 \%$ \\
Very frequently & $5 \%$ & $9 \%$ & $1 \%$ & $4 \%$ & $0 \%$ \\
\hline
\end{tabular}

\section{Table 8}

Distance from Next Closest Library in System

Cross-tabulated with

Overall Perception of Networking/Collaboration Opportunity

Networking/Collaboration Opportunity as Compared to Colleagues

\begin{tabular}{rccccc} 
Distance in Miles & Less & About the same & More & N/A & Other \\
\hline $0-5(n=192)$ & $14 \%$ & $64 \%$ & $18 \%$ & $1 \%$ & $3 \%$ \\
$6-10 \quad(n=40)$ & $18 \%$ & $65 \%$ & $15 \%$ & $3 \%$ & $0 \%$ \\
$11-25 \quad(n=74)$ & $23 \%$ & $51 \%$ & $16 \%$ & $3 \%$ & $7 \%$ \\
$26-50 \quad(n=63)$ & $22 \%$ & $62 \%$ & $16 \%$ & $0 \%$ & $0 \%$ \\
$51-100 \quad(n=54)$ & $28 \%$ & $54 \%$ & $19 \%$ & $0 \%$ & $0 \%$ \\
$100+\quad(n=34)$ & $32 \%$ & $56 \%$ & $12 \%$ & $0 \%$ & $0 \%$ \\
N/A $\quad(n=20)$ & $25 \%$ & $55 \%$ & $20 \%$ & $0 \%$ & $0 \%$ \\
\hline
\end{tabular}




\section{Table 9}

\section{Library Type}

Cross-tabulated with

Frequency of Communication with Librarians at Other Libraries in the System

Frequency of Communication with Other Librarians in the System

\begin{tabular}{lccccc} 
Library Type & Never & Rarely & Occasionally & Frequently & $\begin{array}{c}\text { Very } \\
\text { frequently }\end{array}$ \\
\hline Decentralized (n=132) & $2 \%$ & $7 \%$ & $35 \%$ & $34 \%$ & $22 \%$ \\
Branch/Regional (n=84) & $1 \%$ & $7 \%$ & $20 \%$ & $32 \%$ & $39 \%$ \\
Main (n=214) & $3 \%$ & $13 \%$ & $33 \%$ & $35 \%$ & $17 \%$ \\
Other (n=49) & $8 \%$ & $16 \%$ & $33 \%$ & $20 \%$ & $22 \%$ \\
\hline
\end{tabular}

\section{Table 10}

Library Type

Cross-tabulated with

Frequency of Participation in System Committees, Taskforces, or Workgroups

Frequency of Participation in System Committees, Taskforces, etc.

\begin{tabular}{lrrccc} 
Library Type & Never & Rarely & Occasionally & Frequently & $\begin{array}{c}\text { Very } \\
\text { frequently }\end{array}$ \\
\hline Decentralized $(\mathrm{n}=132)$ & $7 \%$ & $12 \%$ & $28 \%$ & $36 \%$ & $19 \%$ \\
Branch/Regional $(\mathrm{n}=83)$ & $2 \%$ & $12 \%$ & $25 \%$ & $37 \%$ & $23 \%$ \\
Main (n=215) & $4 \%$ & $6 \%$ & $23 \%$ & $38 \%$ & $29 \%$ \\
Other $(\mathrm{n}=53)$ & $15 \%$ & $9 \%$ & $23 \%$ & $25 \%$ & $28 \%$ \\
\hline
\end{tabular}

\section{Table 11}

\section{Library Type}

Cross-tabulated with

Frequency of Networking Opportunities with Colleagues within the System

\begin{tabular}{lccccc}
\multirow{2}{*}{ Library Type } & \multicolumn{5}{c}{ Frequency of Networking Opportunities with Colleagues within System } \\
& Never & Rarely & Occasionally & Frequently & $\begin{array}{c}\text { Very } \\
\text { frequently }\end{array}$ \\
\hline Decentralized (n=132) & $1 \%$ & $15 \%$ & $46 \%$ & $27 \%$ & $11 \%$ \\
Branch/Regional (n=83) & $1 \%$ & $14 \%$ & $35 \%$ & $36 \%$ & $13 \%$ \\
Main (n=215) & $1 \%$ & $10 \%$ & $31 \%$ & $41 \%$ & $16 \%$ \\
Other (n=51) & $4 \%$ & $22 \%$ & $33 \%$ & $27 \%$ & $14 \%$ \\
\hline
\end{tabular}




\section{Table 12}

Number of Degreed Librarians

Cross-tabulated with

Perceived Professional Development Opportunity

Prof. Development Opportunity as Compared to Colleagues

\begin{tabular}{crrrrr}
$\begin{array}{l}\text { Number of Degreed Librarians } \\
\text { at Primary Workplace }\end{array}$ & Less & $\begin{array}{c}\text { About the } \\
\text { same }\end{array}$ & More & N/A & Other \\
\hline $0(\mathrm{n}=2)$ & $50 \%$ & $50 \%$ & $0 \%$ & $0 \%$ & $0 \%$ \\
$1(\mathrm{n}=25)$ & $56 \%$ & $44 \%$ & $0 \%$ & $0 \%$ & $0 \%$ \\
$2(\mathrm{n}=33)$ & $52 \%$ & $39 \%$ & $9 \%$ & $0 \%$ & $0 \%$ \\
$3-5(\mathrm{n}=79)$ & $32 \%$ & $41 \%$ & $22 \%$ & $1 \%$ & $5 \%$ \\
$6-10(\mathrm{n}=101)$ & $18 \%$ & $57 \%$ & $23 \%$ & $0 \%$ & $2 \%$ \\
$11-20(\mathrm{n}=104)$ & $13 \%$ & $65 \%$ & $18 \%$ & $1 \%$ & $2 \%$ \\
$21-35(\mathrm{n}=61)$ & $10 \%$ & $72 \%$ & $18 \%$ & $0 \%$ & $0 \%$ \\
$36-50(\mathrm{n}=39)$ & $5 \%$ & $74 \%$ & $21 \%$ & $0 \%$ & $0 \%$ \\
$51+(\mathrm{n}=37)$ & $11 \%$ & $62 \%$ & $19 \%$ & $0 \%$ & $8 \%$ \\
\hline
\end{tabular}

\section{Table 13}

Perceived Opportunity for Networking and Collaboration Cross-tabulated with

Library Type

Networking/Collaboration Opportunity as Compared to Colleagues

\begin{tabular}{lccccc} 
Library Type & Less & About the same & More & N/A & Other \\
\hline All Respondents $(\mathrm{n}=478)$ & $20 \%$ & $60 \%$ & $17 \%$ & $1 \%$ & $2 \%$ \\
Decentralized $(\mathrm{n}=129)$ & $23 \%$ & $59 \%$ & $16 \%$ & $1 \%$ & $2 \%$ \\
Branch/Regional $(\mathrm{n}=83)$ & $29 \%$ & $49 \%$ & $18 \%$ & $1 \%$ & $2 \%$ \\
Main (n=212) & $15 \%$ & $65 \%$ & $17 \%$ & $1 \%$ & $2 \%$ \\
Other (n=51) & $20 \%$ & $57 \%$ & $18 \%$ & $0 \%$ & $6 \%$ \\
\hline
\end{tabular}




\section{Table 14}

Number of Degreed Librarians

Cross-tabulated with

Perceived Networking/Collaboration Opportunity

Networking/Collaboration Opportunity as Compared to Colleagues

Number of Degreed Librarians

\begin{tabular}{rrrrrc} 
at Primary Workplace & Less & About the same & More & N/A & Other \\
\hline $0 \quad(n=2)$ & $0 \%$ & $100 \%$ & $0 \%$ & $0 \%$ & $0 \%$ \\
$1 \quad(n=26)$ & $62 \%$ & $35 \%$ & $0 \%$ & $4 \%$ & $0 \%$ \\
$2 \quad(n=32)$ & $47 \%$ & $38 \%$ & $16 \%$ & $0 \%$ & $0 \%$ \\
$3-5(n=79)$ & $19 \%$ & $63 \%$ & $14 \%$ & $0 \%$ & $4 \%$ \\
$6-10(n=101)$ & $15 \%$ & $60 \%$ & $21 \%$ & $1 \%$ & $3 \%$ \\
$11-20(n=103)$ & $15 \%$ & $64 \%$ & $18 \%$ & $2 \%$ & $1 \%$ \\
$21-35(n=60)$ & $17 \%$ & $57 \%$ & $23 \%$ & $2 \%$ & $2 \%$ \\
$36-50(n=39)$ & $13 \%$ & $79 \%$ & $8 \%$ & $0 \%$ & $0 \%$ \\
$51+(n=36)$ & $14 \%$ & $56 \%$ & $22 \%$ & $0 \%$ & $8 \%$ \\
\hline
\end{tabular}

\section{Table 15}

Number of Degreed Librarians

Cross-tabulated with

Perceived Isolation

\begin{tabular}{|c|c|c|c|c|c|}
\hline & Perceive & ation $\mathrm{Fl}$ & I Colleagues V & in One’s Oy & rary System \\
\hline $\begin{array}{l}\text { Number of Degreed } \\
\text { Librarians at Primary } \\
\text { Workplace }\end{array}$ & Never & Rarely & Occasionally & Frequently & $\begin{array}{c}\text { Very } \\
\text { frequently }\end{array}$ \\
\hline $0 \quad(n=2)$ & $50 \%$ & $0 \%$ & $50 \%$ & $0 \%$ & $0 \%$ \\
\hline $1 \quad(n=26)$ & $8 \%$ & $15 \%$ & $38 \%$ & $31 \%$ & $8 \%$ \\
\hline $2 \quad(n=32)$ & $16 \%$ & $16 \%$ & $44 \%$ & $22 \%$ & $3 \%$ \\
\hline $3-5 \quad(n=79)$ & $10 \%$ & $23 \%$ & $41 \%$ & $19 \%$ & $8 \%$ \\
\hline $6-10 \quad(n=101)$ & $15 \%$ & $37 \%$ & $24 \%$ & $20 \%$ & $5 \%$ \\
\hline $11-20(n=103)$ & $16 \%$ & $40 \%$ & $28 \%$ & $11 \%$ & $5 \%$ \\
\hline $21-35 \quad(n=60)$ & $27 \%$ & $30 \%$ & $28 \%$ & $5 \%$ & $10 \%$ \\
\hline $36-50 \quad(n=39)$ & $15 \%$ & $36 \%$ & $38 \%$ & $8 \%$ & $3 \%$ \\
\hline $51+\quad(n=36)$ & $5 \%$ & $38 \%$ & $38 \%$ & $16 \%$ & $3 \%$ \\
\hline
\end{tabular}

